2020-02-18

\title{
Understanding Public Attitudes to Hate: Developing and Testing a U.K. Version of the Hate Crime Beliefs Scale
}

\section{Bacon, Alison}

http://hdl.handle.net/10026.1/15326

\section{$10.1177 / 0886260520906188$}

Journal of Interpersonal Violence

SAGE Publications

All content in PEARL is protected by copyright law. Author manuscripts are made available in accordance with publisher policies. Please cite only the published version using the details provided on the item record or document. In the absence of an open licence (e.g. Creative Commons), permissions for further reuse of content should be sought from the publisher or author. 
Authors' version

Accepted for publication in Journal of Interpersonal Violence on 19/01/2020.

Understanding public attitudes to hate: developing and testing a UK version of the Hate

Crime Beliefs Scale.

\author{
Alison M. Bacon, Jon May \& Jaysan J. Charlesford \\ School of Psychology \\ University of Plymouth, UK
}

Corresponding author:

Dr Alison M. Bacon

School of Psychology

University of Plymouth

Drake Circus

Plymouth, Devon, UK

Email: ambacon@plymouth.ac.uk

We have no funding or conflict of interest to declare. 


\begin{abstract}
Against the backdrop of an increase in reported hate crimes, we present the development of a UK focussed instrument designed to evaluate the nature of public beliefs about hate-crime, legislation, offenders and victims. In Study 1, 438 particpants completed an Anglicised version of the Hate Crime Belief Scale (Cabeldue et al, 2018). Factor analyses revealed three subfactors: Denial (high scores represent a denial of hate crime severity and need for legislation), Compassion (high score reflect compassion towards victims and affected communities) and Sentencing (higher scores reflect more punitive attitudes). In Study 2 ( $\mathrm{N}=$ 134) we show that scores on Denial are positively associated with those on Right Wing Authoritarianism (RWA) and Social Dominance Orientation (SDO), ideologies known to be associated with prejudice. Compassion was negatively associated with these ideologies. Mediation analyses showed that Big Five personality traits openness to experience and conscientiousness predicted Denial and Compassion via RWA, while agreeableness and openness predicted scores via SDO, thus supporting the application of the dual-process model of prejudice to hate crime beliefs. Results are discussed in terms of the nature of hate crime beliefs and the importance of understanding public attitudes which may support undesirable social norms and influence jury decision making in trials of hate related offences.
\end{abstract}


The term hate crime is used to describe a range of criminal behaviours where the perpetrator is motivated by hostility or prejudice towards protected characteristics of the victim. In the UK these are currently disability, race, religion, sexual orientation and transgender identity (College of Policing, 2014; for detail of the history of hate crime in the UK and how these characteristics came to be protected, see Walters et al, 2017). In 2017-18, police in England and Wales recorded 94,098 hate crime offences, an increase of 17\% compared with the previous year. This increase is thought to be largely driven by improvements in police recording, although there have been spikes in hate crime following events such as the EU Referendum and the terrorist attacks in 2017 (Home Office, 2018). Race was identified as a motivating factor for more than three quarters of recorded cases $(76 \%)$, followed by sexual orientation (12\%), religion (9\%), disability (8\%) and transgender identity (2\%). The British Crime Survey, which accounts for experiences of victimization not reported to the police, indicates that around 184,000 incidents took place in the same period (Home Office, 2018).

Targets of hate crimes are often emotionally affected, experiencing loss of confidence, vulnerability, fear, difficultly sleeping, anxiety or panic attacks or depression (Home Office, 2018). The trauma of witnessing hate crime can also have damaging effects on family members, particularly children (Williams and Tregidga, 2014; Zempi \& Chakraborti, 2014) and minorities who have not experienced hate crime restructure their daily lives to avoid putting themselves at risk. In the wider community, hate crime can damage social cohesion as groups distance themselves from one another. In recognition of these impacts, the Criminal Justice Act (2003) introduced specific sentencing provisions allowing for "uplifts" (e.g. longer prison sentences), for those found guilty of hate crimes.

In the present research, we are concerned with public perceptions of hate crime and the associated legislation. Understanding this is vital, not least because of the damaging impacts of hate crime for individuals and for wider society, but also because members of the general 
public sit on juries when crimes, including hate crimes, are tried in court. The way that communities respond to hate crimes may also impact how such incidents are dealt with and police can also be influenced by their own opinions (Grattet \& Jenness, 2008). Addressing hate crime requires combatting public beliefs and social norms that support the perpetuation of hate behaviours. Social norm theory describes how behaviour is influenced by what individuals see or hear of others doing (Cialdini \& Goldstein, 2004; Miller \& Prentice, 2016; Wright, et al, 1997). A wealth of research has shown that the perception of what is normal behaviour within a given society or social group triggers and guides action (see Chung, \& Rimal, 2016 for review). Norm-based behavioural interventions are based in the assumption that people are unaware of social norms and their relationship to them. For instance, individuals are often consciously unaware of norms or are mistaken about their relation to them, frequently overestimating the prevalence of many undesirable behaviours. That perception is used as a standard against which to compare their own behaviours. Providing people with information about the behaviour and attitudes of their peers is a strategy commonly employed as a means to changing behaviours considered harmful to individuals (e.g. health behaviours) or to society (e.g. environmentally friendly behaviours; e.g. Miller \& Prentice, 2016; Michie, van Stralen \& West, 2011). Receiving feedback as to whether they are in the majority or in the minority compared to peers can shape an individual's perception of their social group and the evaluative significance of their behaviour (Miller \& Prentice, 2016). It is sometimes claimed that the introduction of anti-discrimination legislation and awareness of prejudice as less socially acceptable has meant that hate beliefs and bias are becoming increasingly covert, subtle, and difficult to detect (Hodson et al, 2005). However, the rising prevalence of hate crime defies this perception and suggests that prejudice against some groups is still embedded within social norms in the UK and elsewhere. 
RUNNING HEAD: HATE CRIME BELIEFS SCALE UK

One powerful influence on social norms is media. The ever-growing prevalence of social media and 24-hour news has meant that the public are more informed about crime (including hate crime) than ever before, whether or not they have experienced it themselves. The UK press in particular gives significant attention to hate incidents and Warren-Gordon (2018) concluded that stringent laws regarding hate crimes might have contributed to the greater amount of print media coverage in this country. Chakraborty (2015) has also highlighted that differences in terms of reported hate crimes across Europe is partly because of the way in which hate crimes are defined and publicized in different countries. Media coverage of high profile cases can have an immediate and sustained impact on the prevalent public values, attitudes, and behaviours (Shah, Domke, \& Wackman, 1996; McCombs, 2005). Newspapers consistently reflect the culture and societal values of a community in their reportage, and consequently, the media representation of social problems has a direct impact on society's perception of them. What is more, the nature of media accounts may in itself inflame public attitudes towards particular groups. For instance, in the UK, religious based offences (often intersecting with racially motivated behaviours) is the most highly reported form of hate crime and Muslim adults are the most likely to be a victim (Home Office, 2018). Responding to the release of these statistics, Dearden (2018) in The Independent newspaper described incidents occurring in Manchester, London Bridge and Parsons Green as "Islamist atrocities". A media which primarily views Muslims through a lens of terrorism and security risk can inflame an increased prevalence of anti-Muslim hate crimes in the immediate aftermath of terrorist incidents (Githens-Mazer \& Lambert, 2010). Media articles rarely highlight sectarian incidents perpetrated by non-Muslims in the same language. Overall, this can lead to the increasing stigmatisation and isolation of UK inhabitants who happen to be Muslim (GithensMazer \& Lambert, 2010). 
Media accounts also influence views of hate crime perpetrators. The impression often conveyed is of hate-fuelled extremists who target their victims in premeditated attacks. However, there is evidence that many perpetrators are ordinary people who offend in the context of their daily life (Iganski, 2008). In these cases, the offence is often driven by everyday frustrations, often at a situation rather than an individual, and where race, sex, disability or other characteristics form an easy target for the venting of annoyance or anger and may not be perceived as hate speech by the perpetrator, who may not understand the impact of their words. Mason (2005) further highlighted how many perpetrators of hate crime are already known to the victim, as neighbours, colleagues or customers, and that a lack of consideration of this context obscures the everyday nature of hate for many individuals.

Eliminating hate crime in society is contingent on combatting public beliefs and attitudes that support social norms and hence the perpetuation of such crimes. Accordingly, a growing body of research aims to understand public attitudes concerning hate offences and associated legislation, especially in the US (e.g., Cramer, et al, 2013; Mallett et al., 2011; Saucier et al, 2017). To this end, Cabeldue, Cramer, Kehn, Crosby, and Anastasi (2018) developed the Hate Crime Beliefs Scale (HCBS), a 40 item psychometric measure which assesses public beliefs across four subscales: Negative Views (i.e., higher scores reflect negative views of legislation and minority group protection), Offender Punishment (i.e., higher scores suggest endorsement of greater punishment), Deterrence (i.e., greater scores denote support for hate-crime legislation as a deterrent of more violence), and Victim Harm (i.e., higher scores reflect pro-victim attitudes). The Negative Views sub-scale displayed predictive utility, such that more negative views of legislation/minority group protection were associated with elevated victim blame, as well as lower perpetrator blame and sentencing recommendations. 
However, while a valuable contribution to the research toolkit, some HCBS items are culturally specific to the US where the scale was developed, for instance several items refer to African Americans and one refers to the First Amendment. Cabeldue et al (2018) acknowledge this limitation and state the need for further developments of the questionnaire outside the US context. Furthermore, none of the items address the issue of religious intolerance against Muslims which has received a good deal of press coverage in the UK. In this paper, we present the Hate Crime Beliefs Scale-UK version (HCBS-UK), an Anglicised version of Cabeldue et al's measure with additional items specifically addressing beliefs about Muslims. In Study 1 we discuss the development of the scale, the factor structure and subscales. In addition, Cabeldue et al presented evidence that liberal political beliefs were positively associated with pro-victim/legislation hate crime attitudes. In terms of the English political system, we therefore predicted that more left wing political orientation would be positively associated with pro victim/legislation beliefs. In Study 2, we test the construct validity of the scale by examining the relationship between scores and those on measures of Social-dominance orientation and Right-wing authoritarianism, factors consistently found to influence social prejudice (see Hodson \& Dhont, 2015, for a review).

\section{Study 1}

\section{Methods}

\section{Participants}

Four hundred and thirty eight participants completed the study. Undergraduate students took part in return for course credit $\left(N=211 ; M_{\text {age }}=20.79, S D=4.14\right.$, range 18-39) of which $186(82 \%)$ were female, 22 male, 3 non-binary and 1 female to male transgender. One hundred and seventy six ( $83 \%)$ described themselves as heterosexual, 5 as gay/lesbian, 24 as bisexual, 6 as other. The majority were White, 205 (96\%), 3 Black, 2 Asian, 1 Other. Most (172, 82\%) described themselves having no religion, a further 29 declared themselves Christian, 1 Muslim, 
1 Buddhist and 1 Other. Students' home locations were spread across the UK, though the majority were from the South West of England (167, 79\%) and a further 23 (10\%) were from London/South East England. In assessing Social-economic status (SES), we used the five category Social Grade model, an occupation based classification produced by the UK Office for National Statistics and which is used widely for market research in the UK. We asked that participants aged under 30 classify the home where they spent most of their childhood (i.e. their family background) while participants aged over 30 rated their present household. One hundred and two (48\%) students rated their background as category A or B (Higher \& intermediate managerial, administrative, professional occupations), 38 (18\%) from category C (Supervisory, clerical, junior managerial, Skilled manual workers) and a similar number, 37, category D (Semi-skilled \& unskilled manual occupations). Sixteen (7.6\%) declared their background as category E (Long-term unemployed for whatever reason). In terms of political views, $100(47 \%)$ described themselves as either slightly, moderately or very left wing, with just $19(9 \%)$ describing their views as right wing. Eighty two students (39\%) stated having no interest in politics and hence no political affiliation. Most students $(150,71 \%)$ had no experience of hate crime while $12(6 \%)$ perceived themselves to have been a victim and 49 $(23 \%)$ knew someone who had been a victim.

General public $\left(N=227 ; M_{\text {age }}=34.74, S D=9.96\right.$, range 18-68 $)$ were recruited through Prolific, a UK based research participation website and paid £3. None of this sample were currently students. One hundred and seventy two (76\%) were female, 54 male and 1 described themselves as non-binary. The majority, $199(88 \%)$, described themselves as heterosexual, 6 as homosexual/gay/lesbian, 14 as bisexual, 2 as asexual and 6 as other. Two hundred (88\%) defined themselves as White, 5 as Black, 11 as Asian, 5 as Mixed-race and 6 as Other. One hundred and thirty two (58\%) described themselves as having no religious affiliation, a further 75 (33\%) described themselves as Christian, 10 Muslim, 1 Jewish, I Hindu, 2 Buddhist and 6 
Other. Participants were based across the UK, with the largest grouping in London/South East of England (58; 26\%), followed by West/East Midlands and eastern England regions. The least represented English region was the South West $(13 ; 6 \%)$. Six participants were from Wales and 5 from Northern Ireland. In terms of SES, 112 (49\%) of these participants rated themselves as being in classes A-B, with $70(31 \%)$ in category C, 23 in category D and 22 from category E. One hundred and twenty five participants (55\%) described their political stance as either slightly, moderately or very left wing, while 61 (27\%) defined themselves as right wing. None of this sample declared having no political interest at all. The majority $(168,74 \%)$ had no personal experience of hate crime, $24(11 \%)$ perceived themselves to have been a victim and 34 knew someone who had been a victim.

\section{Development of HCBS-UK items.}

Cabeldue et al (2018)'s original HCBS and their factor loadings for each item are shown in Table 2. For items which refer to African Americans we retained the original wording other than to amend the term African American to Black, e.g. their item 24 becomes Offenders who target Black people based on their race deserve a longer prison sentence. Item 40 refers to the First Amendment. Here we changed the wording to I do not believe hate crime violates the right to freedom of speech or religion. Finally, item 32 referred to prosecutors pursuing hate crime. We changed this to The police spend too much time pursuing hate crimes, to better reflect UK law enforcement system. In addition we added four new items with structures based in original items but addressing beliefs about those of Muslim faith specifically, these were: Offenders who target Muslims based on their religion deserve a harsher sentence; Offenders who target Muslims based on their race deserve a harsher sentence; Crimes against Muslims receive too much media attention; Hate-crime law protection of Muslims is unnecessary. Additionally, Cabeldue et al's items 12 and 29 state that hate-crime law is unnecessary with regard to transgender and Black people respectively. We added two further items mirroring this 
wording but with reference to other characteristics which seemed to be underrepresented in the original scale: Hate-crime law protection of Jewish people is unnecessary and Hate-crime law protection of people with disabilities is unnecessary. Overall therefore, our final scale, the Revised Hate Crime Beliefs Scale UK version (HCBS-UK), had 46 items. We used the Excel RAND function to generate a new randomised order for presenting these items to participants. All participants received items in this same order and also completed a demographics questionnaire.

\section{Analysis}

Confirmatory Factor Analyses (CFA) used the lavaan package (Roseel, 2012) and semTools (Pornprasertmanit et al., 2016) within R 3.2.4 (R Core Team, 2015). We defined good fit as CFI and TLI $>.90$, SRMR $<.08$ and RMSEA $<.05$, and acceptable fit as approximating these levels (e.g. RMSEA <.10). We examined modification indices to check for items that were substantially cross-loading and see if correlating error terms within subscales further improved model fit. We stopped when acceptable fit was obtained. We provide the data and analysis scripts at https://github.com/jon-may/HateCrime .

\section{Results}

We began by fitting the structure identified by Cabeldue et al (2018) to the original 40 items. Although this model was better fitting than a unifactorial model, it was of borderline acceptability (see Table 1: 4 factor model, 40 items). Modification indices suggested nine items might fit better on different factors, but these changes compromised the factors' identity. We therefore combined the Offender Punishment, Victim Harm and Deterrence factors and seven Negative Beliefs items into two new factors, Compassion and Sentencing, and renamed the remaining Negative Beliefs factor Denial. With this structure, fit was improved and met criteria on all indices except TLI (Table 1: 3 factor model, 40 items). The six novel items were then added, two to Sentencing and four to Denial, and with a total of twelve pairs of error 
covariances correlating, fit met SRMR and RMSEA criteria (Table 1: 3 factor model, 36 items).

Table 1: Robust Fit indices

\begin{tabular}{lrrrrrrr}
\hline & $\chi^{2}$ & df & CFI & TLI & SRMR & RMSEA & AIC \\
\hline Unifactorial 40 items (14) & 2047 & 726 & .773 & .756 & .090 & .070 & 40024 \\
4 factor Model, 40 items (4) & 1729 & 729 & .828 & .816 & .082 & .061 & 39644 \\
3 factor model, 40 items (11) & 1218 & 726 & .916 & .909 & .053 & .042 & 39052 \\
3 factor model, 46 items (9) & 1892 & 977 & .886 & .879 & .053 & .051 & 43867 \\
3 factor model, 20 items (7) & 299 & 159 & .963 & .955 & .054 & .052 & 17993 \\
\hline
\end{tabular}

Notes: CFI: Comparative fit Index; TLI: Tucker-Lewis Index; SRMR: Standardized Root Mean Residual; RMSEA: Root Mean Square Error of Approximation; AIC: Akaike's Information Criterion

To produce a shorter 20-item scale we retained five Sentencing, five Compassion items and ten Denial items with highest item-subscale correlations. Fit criteria remained strong (Table 1: 3 factor model, 20 items) and the subscales each had strong alpha coefficients (Denial .90 , Compassion .76, Sentencing .89). Table 2 presents the final 20 items and their factor loadings from Cabeldue et al (2018) and from our analyses above.

Table 2. The final 20 item HCBS-UK and descriptive statistics. Factor loadings are shown for this and the original scale (Cabeldue et al, 2018; Table 1). ITC is the correlation between the item and its subscale total.

\begin{tabular}{|c|c|c|c|c|c|}
\hline Item & $\begin{array}{l}\text { Original } \\
\text { HCBS } \\
\text { Factor } \\
\end{array}$ & $\begin{array}{l}\text { Revised } \\
\text { HCBS-UK } \\
\text { Factor } \\
\end{array}$ & ITC & Mean & SD \\
\hline $\begin{array}{l}\text { Offenders who target Muslims based on their } \\
\text { race deserve a harsher sentence }\end{array}$ & $\begin{array}{l}\text { Offender } \\
\text { Punishment }\end{array}$ & Sentencing & .77 & 3.4 & 0.97 \\
\hline $\begin{array}{l}\text { A hate-crime offender should receive a } \\
\text { lengthier prison sentence. }\end{array}$ & $\begin{array}{l}\text { Offender } \\
\text { Punishment }\end{array}$ & Sentencing & .73 & 3.5 & 0.94 \\
\hline $\begin{array}{l}\text { Offenders who target Muslims based on their } \\
\text { religion deserve a harsher sentence }\end{array}$ & $\begin{array}{l}\text { Offender } \\
\text { Punishment }\end{array}$ & Sentencing & .72 & 3.5 & 0.95 \\
\hline $\begin{array}{l}\text { Offenders who target black people based on } \\
\text { their race deserve a longer prison sentence. }\end{array}$ & $\begin{array}{l}\text { Offender } \\
\text { Punishment }\end{array}$ & Sentencing & .70 & 3.4 & 0.97 \\
\hline
\end{tabular}


RUNNING HEAD: HATE CRIME BELIEFS SCALE UK

\begin{tabular}{|c|c|c|c|c|c|}
\hline $\begin{array}{l}\text { Evidence of bias motivation in a crime should } \\
\text { be an aggravating factor in sentencing. }\end{array}$ & $\begin{array}{l}\text { Negative } \\
\text { Beliefs }\end{array}$ & Sentencing & .66 & 3.6 & 0.83 \\
\hline Hate-crime victims receive too much attention. & $\begin{array}{l}\text { Negative } \\
\text { Beliefs }\end{array}$ & Denial & .78 & 1.9 & 0.9 \\
\hline $\begin{array}{l}\text { Hate-crime law protection of Muslims is } \\
\text { unnecessary }\end{array}$ & $\begin{array}{l}\text { Negative } \\
\text { Beliefs }\end{array}$ & Denial & .75 & 1.6 & 0.89 \\
\hline $\begin{array}{l}\text { The police spend too much time pursuing hate } \\
\text { crimes. }\end{array}$ & $\begin{array}{l}\text { Negative } \\
\text { Beliefs }\end{array}$ & Denial & .73 & 2 & 0.89 \\
\hline $\begin{array}{l}\text { Crimes against Muslims receive too much } \\
\text { media attention. }\end{array}$ & $\begin{array}{l}\text { Negative } \\
\text { Beliefs }\end{array}$ & Denial & .72 & 2.1 & 1.02 \\
\hline $\begin{array}{l}\text { Hate-crime law protection of Jewish people is } \\
\text { unnecessary }\end{array}$ & $\begin{array}{l}\text { Negative } \\
\text { Beliefs }\end{array}$ & Denial & .72 & 1.7 & 0.85 \\
\hline $\begin{array}{l}\text { Hate-crime law protection of black people is } \\
\text { unnecessary }\end{array}$ & $\begin{array}{l}\text { Negative } \\
\text { Beliefs }\end{array}$ & Denial & .70 & 1.6 & 0.84 \\
\hline $\begin{array}{l}\text { Having to report crimes against transgender } \\
\text { people is unnecessary. }\end{array}$ & $\begin{array}{l}\text { Negative } \\
\text { Beliefs }\end{array}$ & Denial & .70 & 1.6 & 0.74 \\
\hline $\begin{array}{l}\text { I believe hate crimes receive too much } \\
\text { attention. }\end{array}$ & $\begin{array}{l}\text { Negative } \\
\text { Beliefs }\end{array}$ & Denial & .69 & 1.9 & 0.88 \\
\hline $\begin{array}{l}\text { The media makes hate crimes into a bigger } \\
\text { deal than they actually are. }\end{array}$ & $\begin{array}{l}\text { Negative } \\
\text { Beliefs }\end{array}$ & Denial & .67 & 2.2 & 0.96 \\
\hline $\begin{array}{l}\text { Charging someone with a separate hate-crime } \\
\text { charge is excessive prosecution. }\end{array}$ & $\begin{array}{l}\text { Negative } \\
\text { Beliefs }\end{array}$ & Denial & 67 & 2 & 0.93 \\
\hline $\begin{array}{l}\text { Legislation including people with disabilities } \\
\text { will discourage crimes against this group of } \\
\text { people. }\end{array}$ & Deterrence & Compassion & .60 & 3.4 & 0.9 \\
\hline $\begin{array}{l}\text { Crimes against people that are physically } \\
\text { impaired are threatening to the entire } \\
\text { community of people with disabilities. }\end{array}$ & $\begin{array}{l}\text { Negative } \\
\text { Beliefs }\end{array}$ & Compassion & .60 & 4 & 0.87 \\
\hline $\begin{array}{l}\text { Sexual orientation bias-motivated crimes are } \\
\text { threatening to the lesbian, gay, bisexual, } \\
\text { transgender community at large. }\end{array}$ & $\begin{array}{l}\text { Negative } \\
\text { Beliefs }\end{array}$ & Compassion & .58 & 3.9 & 0.87 \\
\hline $\begin{array}{l}\text { Harsh punishments of hate-crime offenders } \\
\text { will decrease the likelihood of future hate } \\
\text { crimes. }\end{array}$ & Deterrence & Compassion & .53 & 3.5 & 0.93 \\
\hline $\begin{array}{l}\text { Hate-crime perpetrators cause psychological } \\
\text { trauma to their victims. }\end{array}$ & $\begin{array}{l}\text { Negative } \\
\text { Beliefs }\end{array}$ & Compassion & .46 & 4.4 & 0.73 \\
\hline
\end{tabular}


We predicted a positive association between left wing political orientation and provictim/legislation attitudes in line with that reported by Cabeldue et al (2018). We coded political beliefs such that a lower score indicated more left wing attitudes and a higher score more right wing attitudes. Bivariate correlations indicated only one significant association, with our compassion scale $(r=-.21, p<.001)$ suggesting that, in line with predictions, those with more right wing attitudes were less compassionate towards victims and the harm that hate crime may cause. Correlations with the other two subscales were not significant (sentencing.08 and denial .07). The vast majority of our sample (99\%) identified as either male or female. Comparing scores across these two groups, males $(M=2.23, S D=.79)$ scored more highly than females $(\mathrm{M}=1.81, \mathrm{SD}=.63)$ on the denial subscale; $\mathrm{t}(431)=4.83, \mathrm{p}<.001)$. Males and females scored comparatively on both compassion and sentencing ( $p>.2$ in both cases). Age was positively associated with both denial $(r=.23)$ and compassion $(r=.46 ; p<.001$ in both cases). The majority $(93 \%)$ of participants reported having no religion $(n=305)$ or being Christian $(n=103)$. Comparing scores across these two groups Christians scored most highly on compassion $t(406)=3.19, p=.002$, and also on denial, though this did not quite reach significance $(\mathrm{p}=.06)$. The groups showed no difference on sentencing $(\mathrm{p}>.03)$. There were too few other religions reported to include in analysis. Similarly, 93\% (405) particpants reported as white, with too few in any other ethnic group to make analysis viable. Finally, we coded experience of hate crime on a scale where $1=$ no experience, $2=$ know someone who has experienced and $3=$ experienced personally, and observed a modest though significant positive association $(r=.12, p=.01)$ suggesting that those who had personal experience of hate crime were most likely to endorse harsh punishment.

\section{Discussion}

Our development of a new HCBS-UK resulted in a shorter, three-factor instrument, compared to that previously developed by Cabeldue et al (2018) in a North American context. 
Our Sentencing factor comprised six items. Five of the items fell within Cabeldue et al's original Offender punishment scale. The sixth item previously fell within their negative beliefs factor, though examination of this item (Evidence of bias motivation in a crime should be an aggravating factor in sentencing) shows the meaning is clearly in line with the others in OP and is reflecting a belief that hate influenced offences should attract a harsher sentence. As such, a higher score on these six items reflects the support for harsher punishments. Cramer, et al., 2013 who showed that severity of sentencing increased when evidence of a hate crime was provided.

Our second factor, Denial, comprises 10 items, all of which are drawn from Cabeldue et al's negative belief factor. However, examination of item content, in our view, reflects a denial of the offence of hate crime itself, or of its importance, rather than simply a negative belief. A high score on the subscale reflects higher level of denial. While several published articles discuss issues such as holocaust denial in the context of hate crime (e.g. Bleich, 2011), relatively few have considered that for some people more everyday hate crime is simply not an issue worthy of concern. Perry (2010) described how although students in her study indicated an awareness of such actions occurring, they did not see it as problematic, with some suggesting that researching hate crime and legislating for it was a waste of time. Perry cited a participant who stated that "undue attention" is itself to blame for creating a false sense of the disparities that might exist. Individuals who oppose legislation often believe that the attention received by hate crimes, in fact, sensationalizes the crime (e.g. Dunbar \& Molina, 2004). This belief also reflects Ditomaso et al's (2003, p. 197) claim that colour blindness “allows whites to ignore, deny, or disregard any notion that race matters in people's lives." Further research could usefully explore the nature of hate crime denial.

Our third factor, which we label compassion, has five items. Three emerged from the reverse worded items within Cabeldue et al's negative beliefs subscale, while the remaining 
two came from their deterrence scale. Compassion has been described as a felt response to suffering that involves caring and an authentic desire to ease distress (Goetz, Keltner \& SimonThomas, 2010), a definition clearly reflected in the scale items. A higher score on this subscale indicates greater compassion for victims and the wider community and the desirability of prevention. Such notions are consistent with literature showing support for increased punishment for hate-crime offenders, along with increased perpetrator blame (e.g., Cramer, et al., 2013). Previous literature has shown that advocates of hate-crime legislation believe that if hate-crime offenders receive harsher sentences, others will be less likely to commit this type of crime in the future (Saucier et al., 2006).

In line with Cabeldue et al, we observed a modest though significant positive association with previous experience of hate crime, with those who had experienced it personality more likely to endorse harsher punishment. Compassion was negatively associated with political orientation such that individuals with right wing views reported less compassion. Males reported more denial than females, broadly in line with previous research on other types of crime. For instance, a meta-analysis by Anderson, Cooper and Okamura (1997) showed more rape acceptance for men while women with experience as, and/or exposure to, rape victims were associated with less rape acceptance. Men are also found to show more acceptance of myths and higher victims blame in cases of prostitution (e.g. Cotton et al, 2002), child sexual abuse (e.g. Cromer \& Freyd, 2007) and human trafficking (Cunningham \& Cromer, 2014). No research to date has examined myths about hate crime. Previous research has also suggested higher rates of compassion generally among women (e.g. Mercadillo et al., 2011). Age showed a positive correlation with both denial and compassion. Anderson et al (1997) showed older people to show higher rape acceptance, but they are also generally found to be more compassionate of others (e.g. Moore et al, 2014). Future research should explore the degree to which these findings are explicable by cohort effects or developmental mechanisms. 
Finally, it is interesting to note that none of the items we retained in our final 20 item measure came from Cabeldue et al's (2018) victim harm subscale, even though both sentencing and compassion items suggest an acknowledgement of the harm done to victims and communities. The failure to retain any of these items might be indicative of cultural differences, such as the US being a more individualist culture, or in specific differences in the social construction of hate crime between the US and UK. Such possibilities might be considered in future research.

Overall, the links with previous research and fit indices reported above suggest that the new HCBS-UK is a robust instrument for measuring hate crime attitudes in terms of Sentencing, Compassion for victims and Denial of the issue. In Study 2 we present a test of the construct validity of the HCBS-UK by examining the relationship between its subscale scores and personality traits previously documented to be associated with prejudice.

\section{Study 2}

When developing their original HCBS, Cabeldue et al (2018) showed that their scale scores showed associations with measures of prejudice against various protected characteristics and social groups. This is useful test of the validity of the questionnaire with their samples. Hate crimes can be thought of as an extreme demonstration of prejudice (Cramer, Wakeman, et al., 2013). While much research on prejudice has focused on the role of social and intergroup influences, over recent years interest in individual and personality factors has increased. Cabeldue et al (2018) presented evidence that scores on all four of their HCBS subscales were related to some form of prejudice, with their negative beliefs scale showing positive associations and the other scales (offender punishment, deterrence and victim harm) presenting negative associations. 
In Study 2, we investigate the relationship between attitudes to hate crime and personality traits found to influence prejudice, those inherent within right-wing ideologies, specifically Right-Wing Authoritarianism (RWA) and Social Dominance Orientation (SDO). Although these RWA and SDO are by no means the only drivers of hate crime, a significant amount of influential research has focused on them and they therefore form useful constructs by which to test the concurrent validity of our new scale. RWA - the sociocultural component of right-wing ideology - comprises a combination of conventionalism, authoritarian aggression, and authoritarian submission (Altemeyer, 1998) and has been found to predict a range of political, social, ideological, and intergroup behviours and attitudes. RWA is a consistent predictor of general prejudice and ethnocentrism (for review see Sibley \& Duckitt, 2008). SDO - the economic component of right-wing ideology - reflects an individual's general attitude toward intergroup relations and whether they prefer such relations to be equal or hierarchical. Measures of SDO assess perceptions that one's own in-group is superior to certain outgroups and therefore should dominate them (Pratto, Sidanius, Stallworth, \& Malle, 1994; Sibley \& Duckitt, 2008). Other research has considered the role of more general personality traits, especially the Big Five: openness to experience (imaginative, preference for variety, openness to different value systems), conscientiousness (impulse control, purposeful, well organised), extraversion (active, excitement seeking, highly sociable), agreeableness (altruistic, empathic, helpful, trusting) and neuroticism (prone to worry, anxiety, depression, angry hostility). The Big Five model of personality is arguably the most widely used in psychology and has been found to explain a wide range of social behviours. In terms of prejudice, the most consistent finding is that openness to experience is negatively associated with prejudice and stereotyping and that higher openness predicts positive intergroup attitudes (Flynn, 2005; McCrae, 1996; Van Hiel \& Mervielde, 2004). Both RWA and SDO correlate 
negatively with Openness, but RWA also correlates positively with Conscientiousness and SDO negatively with Agreeableness (Heaven \& Bucci, 2001).

The dual-process motivation model of prejudice (e.g. Duckitt, 2001; Duckitt \& Sibley, 2010) suggests that SDO and RWA are not personality traits in themselves, but rather dimensions of ideological attitudes that mediate the relationship between traits such as the Big Five and prejudice. They support individual goals or values regarding group-based dominance and superiority (SDO) and social cohesion and collective security (RWA). These two motivational goals are made salient for individuals by a combination of personality and socialisation in certain social contexts (Duckitt, 2001; Duckitt, Wagner, du Plessis, \& Birum, 2002; Cramer \& Duckitt, 2013, Duckitt \& Sibley, 2010). Consistent effects are observed whereby Conscientiousness and (low) Openness predict prejudice via RWA, whereas (low) Agreeableness and low Openness predict prejudice via SDO (Cramer and Duckitt, 2013).

Relatively little work has focussed on individual determinants of hate crime other than social and economic motivations. Levin and McDevitt (1993; 2002) discuss three types of hate crime offender: those who commit their crimes for the excitement or thrill, those who perceived themselves as defending their home or way of life, and those whose life's mission is to rid the world of groups they consider evil or inferior. We can see how SDO and RWA may link to these motivations. The only extant study we are aware of which has examined Big Five traits in the context of hate crime is that of ElSherief, et al (2018) who found that online hate speech instigators presented openness scores associated with low emotional awareness and adventurousness, but a wild imagination. They also had low conscientiousness scores, reflecting a tendency to disregard rules and obligations and to act impulsively, and lower levels of Agreeableness, associated with suspicious and antagonistic behaviors.

In Study 2 we test the integrity of the new HCBS-UK by examining the relationship between scores on its three subscales, RWA, SDO and the Big Five traits. Assuming that 
attitudes to hate crime are associated with prejudice, construct validity of the scale will be indicated by positive associations between HCBS-UK Denial scores and measures of SDO and RWA, and a negative association with openness and agreeableness. Sentencing and Compassion however should present the opposite pattern, negatively associated with SDO and RWA, and positively with openness and agreeableness. In addition, we investigate whether the dual-process model of prejudice (Duckitt \& Sibley, 2010) also applies to hate crime attitudes by testing for mediation of these Big Five effects by RWA and SDO respectively.

\section{Methods}

\section{Participants}

One hundred and thirty four members of the general public took part. They were recruited through the Prolific online research recruitment platform and paid $£ 2.50$ for their time. None had taken part in Study 1 and none declared themselves to be currently students. Mean age was $36.44(\mathrm{SD}=11.32)$. Twenty nine were male, 102 female and 3 reported as gender fluid. The majority were White (123, 92\%), 2 Black, 4 Asian, 4 Mixed race and one other ethnicity. One hundred and seventeen (87\%) reported themselves to be heterosexual, 4 homosexual, 9 bisexual, 4 other. Eighty particpants (60\%) reported having no religion, a further 45 (34\&) reported as Christian, 3 as Muslim, 1 as Hindu, 1 Sikh, 2 Buddhist and 2 other religion. The largest proportion came from London/South East England (29, 22\%), or South west England (20, 15\%). A further 19 (14\%) came from North West England. The reminder came from locations across the UK, including Scotland $(11,8 \%)$ and 2 from Northern Ireland. In terms of SES, 9 reported being from the Higher Managerial/Professional category, 46 (34\% from Intermediate managerial/professional, 36(27\%) from supervisory, clerical, junior management, 18(13\%) from skilled manual, 8(6\%) from unskilled manual and $17(13 \%)$ from long-term unemployed for whatever reason. Finally, 40 (30\%) reported extremely left wing 
views, 79 (59\%) reported central political views and just 3 people (2\%) reported extreme right wing beliefs.

Procedures

Particpants completed the following measures:

Hate Crime Belief Scale - UK (HCBS-UK), final 20 item version as developed in Study 1 above. We observed very good reliability in this study; Denial $\alpha=.92$ Compassion $\alpha=.75$, and Sentencing $\alpha=.83$.

Social Dominance Orientation (SDO) scale (Pratto, et al., 1994). This 16 item scale presents items such as some groups of people are just more worthy than others and we must increase social equality (reverse scored). Participants respond on a 7-point scale where $1=$ Do not agree at all and $7=$ Agree completely and score reflects the mean response, hence the highest possible score is 7 . We observed excellent reliability with the present sample, $\alpha=.91$.

Right Wing Authoritarianism (RWA) scale (Altemeyer, 1998). This twelve item scale presents statements such as There are many radical, immoral people in our country today who are trying to ruin it for their godless purposes, whom the authorities should put out of action. Participants respond on a 7 -point scale where $1=$ Strongly disagree and $7=$ Strongly agree. Score is calculated as the mean response, so the maximum possible score is 7 . We observed very good reliability with this sample, $\alpha=.85$.

Big Five Inventory (BFI; John et al, 1991; 2008) yields scores for each of the Big Five trait dimensions. It lists 44 attributes, e.g. I am someone who is.... talkative, (extraversion, 8 items), helpful and unselfish with others (agreeableness, 9 items), perseveres until the task is finished (conscientiousness, 9 items), worries a lot (neuroticism, 8 items), curious about many different things (openness, 10 items). Participants indicate how much each attribute reflects themselves on a scale where $1=$ disagree strongly and $5=$ Agree strongly. We observed very 
good reliability; Extraversion $\alpha=.89$, Openness $\alpha=.82$, Agreeableness $\alpha=.79$,

Conscientiousness $\alpha=.83$ and Neuroticism $\alpha=.87$.

\section{Results}

Table 3 presents descriptive statistics for the three hate crime attitude factors and other measures.

Table 3. Descriptive statistics for measures in Study 2.

\begin{tabular}{lcccccccccc}
\hline & Compassion & Denial & Sentencing & RWA & SDO & O & E & A & C & N \\
\hline Mean & 3.88 & 1.88 & 3.25 & 5.33 & 5.75 & 3.31 & 2.76 & 3.74 & 3.69 & 3.22 \\
SD & 0.63 & 0.76 & 0.92 & 3.15 & 2.1 & 0.66 & 0.83 & 0.62 & 0.68 & 0.86 \\
\hline \multicolumn{7}{c}{ RWA = right-wing authoritarianism; SDO = social-dominance orientation; O = openness to experience; } \\
E = extraversion; A = agreeableness; C = conscientiousness; N = neuroticism.
\end{tabular}

Table 4 shows correlations between measures. Compassion is negatively associated with both RWA and SDO, and positively with openness to experience. Denial was positively associated with both RWA and SDO and negatively with openness. Sentencing was negatively related to SDO but presented no significant relationship with any other variable.

Table 4. Correlations between all measures in Study 2.

\begin{tabular}{|c|c|c|c|c|c|c|c|c|c|}
\hline & Denial & Sentencing & RWA & SDO & $\mathrm{O}$ & $E$ & $\mathrm{~A}$ & $\mathrm{C}$ & $\mathrm{N}$ \\
\hline Compassion & $-.60 * *$ & $.54 * *$ & $-.30 * *$ & $-.42 * *$ & $.22 * *$ & -.11 & -.003 & -.12 & .10 \\
\hline Denial & & $-.43 * *$ & $.38 * *$ & $.61 * *$ & $-.20 *$ & .06 & -.05 & .08 & -.07 \\
\hline Sentencing & & & -.10 & $-.28 * *$ & .11 & -.003 & .01 & -.08 & .10 \\
\hline RWA & & & & $.41 * *$ & $-.30 * *$ & $.18 *$ & $.27 * *$ & $.42 * *$ & $-.36 * *$ \\
\hline SDO & & & & & $-.19 *$ & .01 & -.13 & .08 & -.12 \\
\hline $\mathrm{O}$ & & & & & & .01 & .03 & -.05 & -.01 \\
\hline $\mathrm{E}$ & & & & & & & $.36 * *$ & $.25 * *$ & $-.36 * *$ \\
\hline $\mathrm{A}$ & & & & & & & & $.44^{* *}$ & $-.56^{* *}$ \\
\hline $\mathrm{C}$ & & & & & & & & & $-.49 * *$ \\
\hline
\end{tabular}


We conducted six regression analyses, two on each of the three Hate Crime factors. Results are shown in Table 5. In each case we entered the Big Five at stage 1 and either RWO or SDO at Stage 2. The results are shown in Table 5. For denial, the only independent predictor at stage 1 was openness. When RWA was added at stage 2 , the model was significantly improved, $\Delta \mathrm{R}^{2}=.11, \mathrm{~F}(1,127)=17.27, \mathrm{p}<.001$, and RWA appeared to mediate the effect of openness. When we repeated this process with SDO entered at stage 2, we found a similar result with SDO mediating the effects of openness in model $2, \Delta \mathrm{R}^{2}=.32, \mathrm{~F}(1,127)=$ 66.84, $\mathrm{p}<.001$. With compassion, similar effects were observed in terms of RWA; $\Delta \mathrm{R}^{2}=.03$, $\mathrm{F}(1,127)=3.78, \mathrm{p}=.05$, and SDO; $\Delta \mathrm{R}^{2}=.13, \mathrm{~F}(1,127)=21.41, \mathrm{p}<.001$. Finally, as Table 5 indicates, for attitudes regarding Sentencing no significant effects were observed in Stage 1 of the regression which accounted for negligible variance. When RWA was added this made little difference, $\Delta \mathrm{R}^{2}=.001, \mathrm{~F}(1,127)=.18, \mathrm{p}=.67$. When $\mathrm{SDO}$ was added at stage 2 , it showed a significant independent effect on Sentencing, but no other significant effects were observed, $\Delta \mathrm{R}^{2}=.06, \mathrm{~F}(1,127)=8.04, \mathrm{p}=.01$. 
RUNNING HEAD: HATE CRIME BELIEFS SCALE UK

Table 5. Regression analyses on Denial, Compassion and Sentencing

\begin{tabular}{|c|c|c|c|c|c|c|c|c|c|c|c|c|c|c|c|c|}
\hline & \multirow[t]{2}{*}{ Denial } & \multirow[b]{2}{*}{ Beta } & \multirow[b]{2}{*}{ Sig. } & \multicolumn{2}{|c|}{$95 \% \mathrm{CI}$} & \multirow{2}{*}{$\begin{array}{l}\text { Adj. } \\
\mathrm{R}^{2}\end{array}$} & \multicolumn{2}{|c|}{ Compassion } & \multicolumn{2}{|c|}{$95 \% \mathrm{CI}$} & \multirow{2}{*}{$\begin{array}{l}\text { Adj. } \\
\mathrm{R}^{2}\end{array}$} & \multicolumn{2}{|c|}{ Sentencing } & \multicolumn{2}{|c|}{$95 \% \mathrm{CI}$} & \multirow{2}{*}{$\begin{array}{r}\text { Adj } \\
\mathrm{R}^{2} \\
\end{array}$} \\
\hline \multirow{6}{*}{1} & & & & lower & upper & & Beta & Sig. & lower & upper & & Beta & Sig. & lower & upper & \\
\hline & $\mathrm{O}$ & -0.198 & 0.023 & -0.425 & -0.032 & & .218 & .012 & .047 & .371 & & .105 & .232 & -.095 & .387 & \\
\hline & $\mathrm{E}$ & 0.064 & 0.497 & -0.112 & 0.23 & & -.096 & .302 & -.214 & .067 & & .031 & .746 & -.175 & .244 & \\
\hline & A & -0.149 & 0.169 & -0.448 & 0.079 & & .112 & .297 & -.102 & .332 & & .101 & .361 & -.173 & .473 & \\
\hline & $\mathrm{C}$ & 0.075 & 0.457 & -0.14 & 0.31 & & -.087 & .389 & -.266 & .104 & & -.053 & .608 & -.348 & .204 & \\
\hline & $\mathrm{N}$ & -0.098 & 0.38 & -0.281 & 0.108 & .03 & .089 & .422 & -.095 & .225 & .04 & .145 & .203 & -.084 & .393 & -.01 \\
\hline \multirow[t]{6}{*}{2} & $\mathrm{O}$ & -0.084 & 0.329 & -0.292 & 0.099 & & .162 & .071 & -.014 & .324 & & .060 & .488 & -.155 & .322 & \\
\hline & $\mathrm{E}$ & 0.055 & 0.537 & -0.111 & 0.212 & & -.092 & .320 & -.210 & .069 & & .034 & .718 & -.167 & .241 & \\
\hline & A & -0.167 & 0.104 & -0.454 & 0.043 & & .121 & .257 & -.091 & .338 & & .025 & .818 & -.286 & .362 & \\
\hline & $\mathrm{C}$ & -0.037 & 0.708 & -0.262 & 0.179 & & -.032 & .759 & -.220 & .161 & & -.032 & .754 & -.312 & .227 & \\
\hline & $\mathrm{N}$ & -0.023 & 0.832 & -0.206 & 0.166 & & .052 & .639 & -.123 & .199 & & .084 & .454 & -.147 & .326 & \\
\hline & RWA & 0.397 & 0 & 0.172 & 0.484 & .14 & -.193 & .054 & -.268 & .002 & .06 & -.254 & .005 & -.440 & -.078 & -.01 \\
\hline \multirow[t]{6}{*}{2} & $\mathrm{O}$ & -0.092 & 0.199 & -0.268 & 0.056 & & .149 & .066 & -.009 & .296 & & .060 & .488 & -.155 & .322 & \\
\hline & $\mathrm{E}$ & 0.058 & 0.449 & -0.086 & 0.192 & & -.092 & .287 & -.201 & .060 & & .034 & .718 & -.167 & .241 & \\
\hline & $\mathrm{A}$ & 0.029 & 0.750 & -0.185 & 0.256 & & -.002 & .983 & -.210 & .205 & & .025 & .818 & -.286 & .362 & \\
\hline & $\mathrm{C}$ & 0.025 & 0.761 & -0.155 & 0.212 & & -.054 & .562 & -.223 & .122 & & -.032 & .754 & -.312 & .227 & \\
\hline & $\mathrm{N}$ & 0.045 & 0.626 & -0.121 & 0.201 & & -.003 & .978 & -.154 & .149 & & .084 & .454 & -.147 & .326 & \\
\hline & SDO & 0.601 & 0.000 & 0.386 & 0.632 & .36 & -.386 & .000 & -.387 & -.155 & .17 & -.254 & .005 & -.440 & -.078 & .05 \\
\hline
\end{tabular}


The dual process approach (Duckitt \& Sibley 2001; 2008; 2010) suggests that low Openness and Conscientiousness influence prejudice via RWA and that low openness and agreeableness predict prejudice via SDO. We tested for these specific mediating effects on Denial and Compassion hate crime beliefs using the PROCESS procedure (Hayes, 2013). The model on the left of Figure 1 shows significant mediating effects suggesting that lower levels of openness will result in higher Denial via RWA, $\beta=-.13,95 \%$ CI $[-.27,-.05]$ and also that higher levels of conscientiousness result in Denial via RWA, $\beta=.13,95 \%$ CI $[.05, .24]$. No significant mediating effects on Compassionate beliefs were observed. On the right of Figure 1, analysis of the effects of trait openness and agreeableness via SDO are presented. Significant indirect effects via SDO are presented between both traits and Denial, openness $\beta=-.12,95 \%$ CI [-.27, -.01] and agreeableness $\beta=-.22,95 \%$ CI [-.43, -.05]. Significant mediating effects of SDO on Compassion were also observed, openness $\beta=.0795 \%$ CI $[.01, .17]$, and agreeableness $\beta=.12,95 \%$ CI $[.03, .27]$.
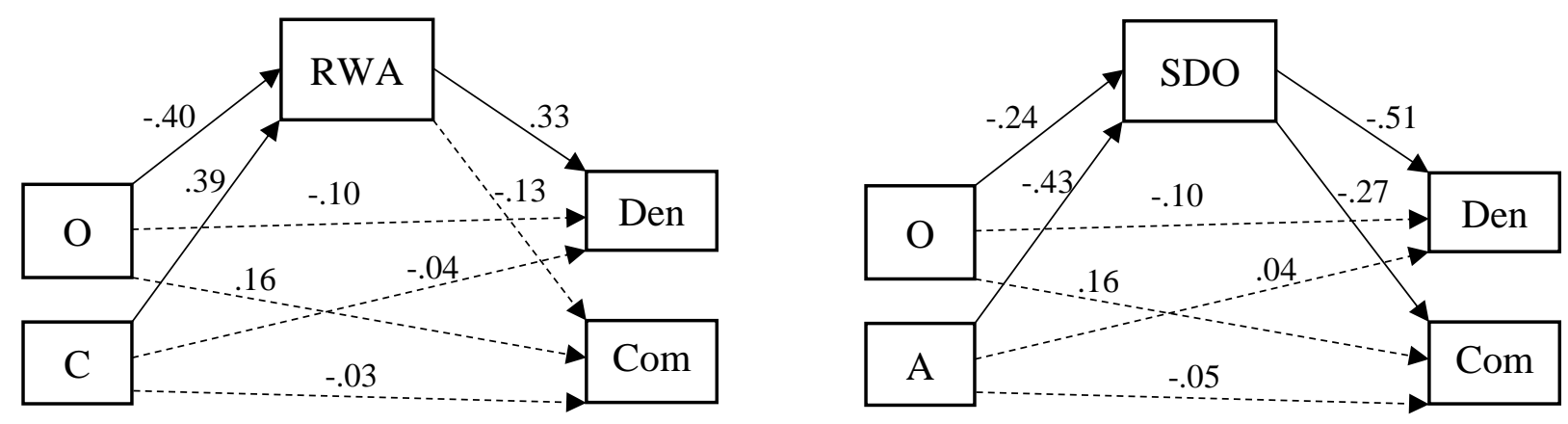

Figure 1. Mediation models showing indirect effects via RWA and SDO on Denial (Den) and Compassion (Com) beliefs. Solid lines indicate significant effects. $\mathrm{O}=$ Openness to experience; $\mathrm{C}=$ Conscientiousness; $\mathrm{A}=$ Agreeableness.

\section{Discussion}

The first aim of Study 2 was to test the construct validity of the new HCBS-UK by examining the relationship between scores on the three factors and those on measures of RWO and SDO, both traits known to influence prejudice, and hence we assumed also hate crime. Our 
analysis supported this aim. Both RWO and SDO were positively associated with the Denial subfactor which assesses negative attitudes towards hate crime legislation and designated groups. The other factors, Compassion and Sentencing present measures of positive attitudes towards designated groups and are supportive of legislation to control hate crime. Compassion was negatively associated with both RWA and SDO as predicted, while Sentencing only presented this relationship with SDO.

Our second aim was to examine whether previous findings relating to the Big Five traits and prejudice, would be replicated with regard to hate crime. We found no significant direct effects of Consciousness or Agreeableness on hate crime attitudes, however the Denial factor was associated with low Openness, while Compassion was associated with high Openness. This supported our predictions and earlier research on prejudice which has consistently found that higher Openness predicts positive intergroup attitudes (e.g. Flynn, 2005; McCrae, 1996; Van Hiel \& Mervielde, 2004). Furthermore, in line with the dual-process motivation theory of prejudice, low Openness predicted hate crime Denial indirectly via both RWA and SDO. Conscientiousness influenced Denial via RWA, but not Compassion. Finally, Agreeableness influenced both Denial and Compassion via SDO. For Sentencing-related attitudes, no significant effects were observed. Overall, we can conclude that the dual-process motivation hypothesis (Duckitt, 2001; Duckitt \& Sibley, 2010) applies to some aspects of hate crime attitudes in a similar way to how it explains prejudice in general. Further application of this model to hate crime might be fruitful.

Furthermore, we suggest that RWA and SDO, should exert subtly different effects on hate crime attitudes as a function of the specific groups under scrutiny. High RWAs, who are motivated to conform to and protect the status quo as a reaction to the 'dangerous' world they perceive, are particularly prejudiced against groups who they perceive threaten existing social structures. Importantly, this might be seen to include some groups protected by hate crime 
legislation, for instance, Muslims are frequently portrayed in both mainstream and social media as threatening 'British' values and traditions (El-Farra, 1996). RWAs may therefore be more supportive of hate crimes against groups who they see as most threatening to the social order (e.g., radical as opposed to moderate Muslims). Conversely, SDOs' belief in life as a 'competitive jungle' where groups must compete to survive, may be motivated to derogate groups they perceive as low-status groups (e.g., people with disabilities. We advocate a future direction in hate crime research that considers specific social targets, or hate crimes with specific underlying motivations (cf. Levin and McDevitt, 1993, 2002).

\section{General Discussion}

Understanding public attitudes towards hate crime is important to consider in the context of community demands on police, jury decision making in trials of hate crime offences and also because such attitudes feed into social norms regarding behaviors towards different social groups. These studies aimed to develop and validate a UK version of Cabeldue et al (2018)'s Hate Crime Belief Scale. This new scale was found to comprise three robust factors, Denial, Compassion and Sentencing (as opposed to four factors in the original version). These subscales represent denial of the severity of hate crime and the harm it causes, compassion towards victims and affected communities and punitive attitudes towards sentencing. Scores on these factor scales presented associations with those on traits known to be associated with prejudice in line with previous research. Scores on the Denial factor are positively associated with those on both RWA and SDO, widely accepted to be indicators of prejudice, but negatively associated with openness to experience which is usually linked to tolerance. Compassion scores were negatively associated with RWA and SDO and positively with openness. Furthermore, Duckitt and Sibley's dual process model of prejudice whereby Big Five traits openness to experience, consciousness and agreeableness account for attitudes via either RWA or SDO also applies to hate crime Denial and Compassion beliefs as measured 
with our scale. Altogether our results suggest that the HCBS-UK can be recommended for use in future research in a UK context as a robust measure of three aspects of hate crime attitudes.

The one factor which did not fit with all our expectations was attitudes to Sentencing, which presented only a negative association with SDO. That individuals with the most punitive attitudes seem to be those with lower levels of SDO, suggests a generally magnanimous character, possibly with wider societal concerns as opposed to personal grudges. However, Gerber and Jackson (2015) suggested that punitive sentiment was related to RWA and arises out of conformity, adherence to conservative moral values and concerns about collective security and cohesion. They did not consider SDO specifically, however their results suggest punitiveness as measured in our scale may differ from the form they discuss. We observed no association between sentencing beliefs and any demographic variables or Big Five traits, however, sentencing scores were possibly related to personal experience of hate crime, a variable not associated with either of the other subscales. One possibility is that experience of hate crime fuels a harsher attitude towards sentencing, though recent work has suggested that exposure to crime does not make for more punitive attitudes (Kleck \& Jackson, 2017) and that ideology and media influences are more important. Further investigation into the association between scores on this sentencing subscale, general attitudes towards crime, and experience of it, are worthy of further study. A more fine grained examination of the Big Five traits, encompassing subfacet scores, may also reveal more about this type of belief. It may be that scores on this subscale reflect generally punitive attitudes towards crime. As such, the factor still applies to hate crime beliefs and is useful measure, but we might not necessarily expect to see much relationship between scores and those on traits known to influence beliefs about prejudice and/or hate crime specifically. Overall however, it is important to note that Study 1 clearly indicated a distinct factor and questionnaire items evidently reflect beliefs about harsher sentencing for hate related offences. As such, the sentencing subfactor clearly applies to hate 
crime beliefs and is a useful measure alongside the other two factors. Future research might benefit from considering the role of other ideology-relevant constructs which are relevant to prejudice more distally. For instance individuals high in system justification (Sibley, 2010) may be less inclined to use (hate crime) legislation to address societal inequities, whereas those higher in just-world belief may be more supportive of hate crime uplifts as a means of redressing the extra harm to victims (Gromet, 2012).

These studies are not without limitations. Firstly, although a strength of the research is that we employed general public participants (as opposed to, say, student populations) our samples comprised mostly individuals who identified as white and female (as is typical of volunteer participant samples). Although research on hate crime perpetrators in the UK has tended to find the majority are white (e.g. Iganski \& Smith, 2011; Wilcox et al., 2010), they also tend to be male. Controlling for demographic factors appeared to have little influence on our results, however the relatively few males in the sample may have led to a degree of bias and this should be acknowledged. In this respect, our studies share the limitations acknowledged by Cabeldue et al (2018) in that particpants were not particularly diverse. Whereas our results provide valuable insight into how majority members - who by definition are most likely to be jurors and law enforcers perceive hate crime, a more diverse sample may further enhance the breadth of this promising research by expanding understanding of how factors such as sex, race and personal experience of hate crime may influence beliefs. Secondly, although Study 2 presents useful evidence for concurrent validity of the HCBS-UK, it is important to acknowledge that RWA and SDO are not the only drivers of prejudice and hate crime. It will be fruitful to investigate how attitudes measured with this new scale are associated with other socio-personality factors such as left-wing antifascism, or the pressures associated with strain theory (Agnew, 2006), whereby hate offences are assumed as a response to perceived social threats by minority groups (e.g. competition for jobs or housing). 
In conclusion, in these studies we extend the work of Cabeldue et al (2018) in presenting a new measure of beliefs about Hate Crime developed within a UK context. We further provide support for the dual-process motivation model of prejudice while extending its potential utility to include the explanation of attitudes towards hate crime. Importantly, the new HCBS-UK appears a robust instrument for the measurement of beliefs associated with denial of hate crime severity, compassion towards victims and the belief in harsher sentencing. Research is now required to further validate the scale with new populations, establish predictive validity through the use of behavioral measures and to obtain greater understanding of the processes by which these beliefs influence real-world behavior. 


\section{References}

Agnew, R. (2006). Pressured into Crime: An Overview of General Strain Theory. Oxford, Oxford University Press.

Altemeyer, B. (1998). The other "authoritarian personality". Advances in Experimental Social Psychology, 30, 47-92.

Anderson, K.B., Cooper, H. \& Okamura, L. (1997). Individual differences and attitudes toward rape: A Meta-Analytic Review. Personality and Social Psychology Bulletin, 23, 295-315.

Bleich, E. (2011). The Rise of Hate Speech and Hate Crime Laws in Liberal Democracies, Journal of Ethnic and Migration Studies, 37, 917-934.

Cabeldue, M. K., Cramer, R. J., Kehn, A., Crosby, J. W., \& Anastasi, J. S. (2018). Measuring attitudes about hate: Development of the hate crime beliefs scale. Journal of Interpersonal Violence, 33, 3656-3685.

Chakraborty, N. (2014). Re-thinking Hate Crime: Fresh Challenges for Policy and Practice. Journal of Interpersonal Violence, 30, 1738-1754.

Chung, A. \& Rimal, R.N. (2016). Social norms: a review. Review of Communication Research, $4,1-28$.

Cialdini, R.B. \& Goldstein, N.J. (2004). Social influence: Compliance and conformity. Annual Review of Psychology, 55, 591-622.

College of Policing. (2014). National Policing Hate Crime Strategy. Retrieved 15/04/2019 from http://library.college.police.uk/docs/college-of-policing/National-Policing-HateCrime-strategy.pdf

Cotton, A., Farley, M., \& Baron, R. (2002). Attitudes toward prostitution and acceptance of rape myths. Journal of Applied Social Psychology, 32, 1790-1796.

Cramer, R. J., Miller, A. K., Amacker, A. M., \& Burks, A. C. (2013). Openness, rightwing authoritarianism, and antigay prejudice in college students: A mediation model. Journal of Counseling Psychology, 60, 64-71.

Cromer, L.D. \& Freyd, J.J. (2007). What Influences Believing Child Sexual Abuse Disclosures? The Roles of Depicted Memory Persistence, Participant Gender, Trauma History, and Sexism. Psychology of Women Quarterly, 31, 13-22.

Cunningham, K.C. \& Cromer, L.D. (2014). Attitudes About Human Trafficking: Individual Differences Related to Belief and Victim Blame. Journal of Interpersonal Violence, 31, 228-244. 
Dearden, L. (2018). Religious hate crime rises $40 \%$ in England and Wales - with more than half directed at Muslims. Article published in The Independent, 16th October 2018. Retrieved on 15/04/2019 from https://www.independent.co.uk/news/uk/crime/uk-hate$\underline{\text { crime-religious-muslims-islamophobia-police-racism-a8585846.html }}$

Ditomaso, N., Parks-Yancy, R. \& Post, C. (2003). White Views of Civil Rights: Color Blindness and Equal Opportunity. In A. Doane \& E. Bonilla-Silva (Eds.). White Out: The Continuing Significance of Racism (pp. 189-198). Routledge: New York.

Duckitt, J. (2001). A dual-process cognitive-motivational theory of ideology and prejudice. In M. P. Zanna, (Ed.), Advances in experimental social psychology (Vol. 33, pp. 41-113). New York: Academic Press.

Duckitt, J., Wagner, C., du Plessis, I., \& Birum, I. (2002). The psychological bases of ideology and prejudice: Testing a dual process model. Journal of Personality and Social Psychology, $83,75-93$.

Duckitt, J., \& Sibley, C. G. (2007). Right wing authoritarianism, social dominance orientation and the dimensions of generalized prejudice. European Journal of Personality, 21, 113-130.

Duckitt, J. \& Sibley, C.G. (2010). Personality, Ideology, Prejudice, and Politics: A DualProcess Motivational Model. Journal of Personality, 78, 1861-1894.

Dunbar, E. \& Molina, A. (2004). Opposition to the Legitimacy of Hate Crime Laws: The Role of Argument Acceptance, Knowledge, Individual Differences, and Peer Influence. Analyses of Social Issues and Public Policy, 4, 91 - 113.

ElSherief, M., Kulkarni, V., Nguyen, D., Wang, W.Y. \& Belding, E. (2018). Hate Lingo: A Target-based Linguistic Analysis of Hate Speech in Social Media. Twelfth International AAAI Conference on Web and Social Media (ICWSM 2018).

Flynn, F.J. (2005). Having an Open Mind: The Impact of Openness to Experience on Interracial Attitudes and Impression Formation. Journal of Personality and Social Psychology, 88, 816-826.

Gerber, M.M. \& Jackson, J. (2016) Authority and Punishment: On the Ideological Basis of Punitive Attitudes towards Criminals, Psychiatry, Psychology and Law, 23, 113-134.

Githens-Mazer, J. \& Lambert, R. (2010). Islamophobia and Anti-Muslim Hate Crime: a London Case Study. University of Exeter, European Muslim Research Centre. Retrieved on 16/04/2019 from http://library.college.police.uk/docs/Hate-crime-report-London.pdf

Goetz, J.L., Keltner, D., Simon-Thomas, E. (2010). Compassion: An evolutionary analysis and empirical review. Psychological Bulletin, 136, 351-374. 
Grattet, R., \& Jenness, V. (2008). Transforming symbolic law into organizational action: Hate crime policy and law enforcement practice. Social Forces, 87, 501-527.

Green, D.P., Glaser, J. \& Rich, A. (1998). From Lynching to Gay-Bashing: The Elusive Connection between Economic Conditions and Hate Crime. Journal of Personality and Social Psychology, 75, 82-92.

Gromet, D. M. (2012). Restoring the victim: Emotional reactions, justice beliefs, and support for reparation and punishment. Critical Criminology, 20, 9-23.

Hodson, G., Hooper, H., Dovidio, J.F. \& Gaertner, S.L. (2005). Aversive racism in Britain: The use of inadmissible evidence in legal decisions. European Journal of Social Psychology, 35, $437-448$.

Hodson, G., \& Dhont, K. (2015). The person-based nature of prejudice: Individual difference predictors of intergroup negativity. European Review of Social Psychology, 26, 1-42.

Home Office, (2018). Hate Crime, England and Wales, 2017/18. Statistical Bulletin 20/18. Retrieved 15/04/2019 from https://assets.publishing.service.gov.uk/government/uploads/system/uploads/attachment_dat a/file/748598/hate-crime-1718-hosb2018.pdf

Iganski, P. (2008). Hate Crime in the City. Bristol: Policy Press.

Iganski, P. \& Smith, D. (2011). Rehabilitation of Hate Crime Perpetrators: Research Report. Equality and Human Rights Commission, Scotland.

John, O. P., Donahue, E. M., \& Kentle, R. L. (1991). The Big Five Inventory-Versions 4a and 54. Berkeley, CA: University of California, Berkeley, Institute of Personality and Social Research.

John, O. P., Naumann, L. P., \& Soto, C. J. (2008). Paradigm shift to the integrative Big Five trait taxonomy: History, measurement, and conceptual issues. In O. P. John, R. W. Robins, \& L. A. Pervin (Eds.), Handbook of Personality: Theory and Research (pp. 114-158). New York, NY: Guilford Press.

Kleck, G. \& Jackson, D.B. (2017). Does crime cause punitiveness? Crime \& Delinquency, 63, $1572-1599$.

Mallett, R. K., Huntsinger, J. R., \& Swim, J. K. (2011). The role of system justification motivation, group status and system threat in directing support for hate crimes legislation. Journal of Experimental Social Psychology, 47, 384-390.

Mason, G. (2005). Hate crime and the image of the stranger. British Journal of Criminology, $45,837-859$. 
McCombs, M. (2005). The agenda setting function of the press. In G. Overholser \& Jamieson, K.H., (Eds.). Institutions of American Democracy: The Press (pp. 156-168). New York: Oxford University Press.

McCrae, R. R. (1996). Social consequences of experiential openness. Psychological Bulletin, $120,323-337$.

McDevitt, J., Levin, J. \& Bennett, S. (2002). Hate Crime Offenders: An Expanded Typology. Journal of Social Issues, 58, 303-317.

Mercadillo, R.E., Díaz, J.L., Pasaye, E.H. \& Barrios, F.A. (2011). Perception of suffering and compassion experience: Brain gender disparities. Brain and Cognition, 76, 5-14.

Miller, D.T. \& Prentice, D.A. (2016). Changing norms to change behavior. Annual Review of Psychology, 67, 339-361.

Michie, S., van Stralen, M. M. \& West, R. (2011). The behaviour change wheel: A new method for characterising and designing behaviour change interventions. Implementation Science. https://implementationscience.biomedcentral.com/articles/10.1186/1748-5908-6-42

Perry, B. (2010). "No biggie": The denial of oppression on campus. Education, Citizenship, and Social Justice, 5, 265-279.

Perry, B., Perry, J., Schweppe, J. \& Walters, M. (2015). Introduction. Understanding hate crime: research, policy and practice. Criminal Justice Policy Review, 27, 571-576.

Pratto, F., Sidanius, J., Stallworth, L. M., \& Malle, B. F. (1994). Social dominance orientation: A personality variable predicting social and political attitudes. Journal of Personality and Social Psychology, 67, 741.

Saucier, D. A., Brown, T. L., Mitchell, R. C., \& Cawman, A. J. (2006). Effects of victims' characteristics on attitudes toward hate crimes. Journal of Interpersonal Violence, 21, 890909.

Saucier, D.A., Hockett, J,M., O’Dea, C.J. \& Miller, S.S. (2017). The Racism Justification Hypothesis and Attitudes Toward Hate Crime Legislation. In E. Dunbar, Blanco, A. \& D.A. Crevecoeur-MacPhail (Eds.). The Psychology of Hate Crimes and Domestic Terrorism (pp. 283-386). Praeger: Santa Barbara.

Shah, D.V., Domke, D. \& Wackman, D.B. (1996). "To Thine Own Self Be True”: Values, Framing, and Voter Decision-Making Strategies. Communication Research, 23, 509-560.

Sibley, C. G. (2010). The dark duo of post-colonial ideology: A model of symbolic exclusion and historical negation. International Journal of Conflict and Violence (IJCV), 4, 106-123.

Sibley, C.G. \& Duckitt, J. (2008). Personality and prejudice: a meta-analytic review.

Personality and Social Psychology Bulletin, 12, 248-279. 
Van Hiel, A., \& Mervielde, I. (2004). Openness to experience and boundaries in the mind: Relationships with cultural and economic conservative beliefs. Journal of Personality, 72, 659-686.

Walters, M., Wiedlitzka, S., Owusu-Bempah, A. \& Goodall, K. (2017). Hate Crime and the Legal Process: Options for Law Reform, University of Sussex.

Warren-Gordon, K. (2018). Perceiving Hate Crimes: A Comparative Analysis of Major Newspaper Coverage of Hate Crimes in the United States and the United Kingdom. International Journal of Criminal Justice Sciences, 13, 172-180.

Wilcox, A., Smithson, H., Christmann, K., Monchuk, L. \& Wong, K. (2010). Racially Motivated Offending and Targeted Interventions. London: Youth Justice Board.

Williams, M.L. \& Tregidga, J. (2013). Hate Crime Victimization in Wales: Psychological and Physical Impacts Across Seven Hate Crime Victim Types. The British Journal of Criminology, 54, I 946-967.

Wright, S.C, Aron, A, McLaughlin-Volpe, T, \& Ropp, S.A. (1997). The extended contact effect: Knowledge of cross-group friendships and prejudice. Journal of Personality and Social Psychology, 73, 73-90.

Zempi, I. \& Chakraborti, N. (2014). Islamophobia, Victimisation and the Veil. Palgrave Macmillan UK. 